\title{
기후변화시나리오와 ETCCDI지수를 이용한 제주지역의 극한기후 분석 Future Extreme Climate Analysis of Jeju Using Climate Change Scenario and ETCCDI Index
}

\author{
정진우* . 정세진** . 김병식*** \\ Jeong, Jin Woo*, Jeung, Se Jin ${ }^{* *}$, and Kim, Byung Sik ${ }^{* * *}$
}

\begin{abstract}
According to the fifth IPCC report, artificial greenhouse gases are at their highest level since they were first observed, and climate change is expected to have a significant impact on the ecosystem, necessitating a response from Korea. For the purpose of this study, Jeju Island was selected as the target area; the annual average precipitation of the region exhibited a $10 \%$ increase from $1,780 \mathrm{~mm}$ in 1991 to $1,961 \mathrm{~mm}$ in 2019 ; the annual average temperature increased by $0.3{ }^{\circ} \mathrm{C}$ over 10 years from 1961 to 2019 . There are three weather stations (Jeju, Seogwipo, and Seongsan) on Mt. Halla, which is $1,950 \mathrm{~m}$ above sea level; among these stations, Jeju Island's climate patterns are the most atypical. The World Meteorological Organization's (WMO) Expert Team on Climate Change Detection and Indices (ETCCDI) for Jeju Island's extreme climate analysis used 8 of the 27 indexes that are most closely related to climate. For analysis purposes, existing RCP 8.5 climate change scenario data were categorized as: past (data analyzed from 1991 to 2019), and future (data analyzed from 2020 to 2100). According to the extreme climate analysis, Jeju Observatory recorded its highest temperature at $25{ }^{\circ} \mathrm{C}$ while exhibiting an increasing trend, and at Seongsan, highest temperature of less than $0{ }^{\circ} \mathrm{C}$ was recorded for more than 40 days in 1996. According to the climate change scenario, the number of hot days in Jeju, Seogwipo, and Seongsan is increasing, but the number of frost days has converged to zero with the progression of the second half of the 21 st century. Japan's highest temperature chart shows that $40{ }^{\circ} \mathrm{C}$ spike in Jeju compared to other regions. Thus, this study highlights the necessity of considering the climate characteristics of each observatory, and the implementation of urban planning and disaster prevention measures.
\end{abstract}

Key words : Jeju Island, Climate Change, ETCCDI, Climate Change Scenario

\section{요 지}

IPCC 5 차 보고서에 따르면 인위적으로 배출되는 온실가스가 관측 이래 최고치를 기록하고 있어, 기후변화가 생태계에 지대한 영향을 미칠 것으로 예상하였다. 따라서 우리나라도 기후변화에 따른 대비를 하여야 한다. 본 논문의 대상지역으로 제주도를 선정하였으며, 제주도의 연평균 강수량은 1991년 1,780 mm에서 2019년 $1,961 \mathrm{~mm}$ 로 약 $10 \%$ 증가하였으며, 연평균 기온은 1961년부터 2019년까지 10 년 동안 $0.3{ }^{\circ} \mathrm{C} / 10$ 년 증가하였다. 제주도의 기후의 특성은 해발 $1,950 \mathrm{~m}$ 인 한라산을 기준으로 3 개소의 기상관측소(제주, 서귀포, 성산)의 기후가 상이하여 타 지역에서는 볼 수 없는 특별한 모습을 보여주고 있다. 제주도의 극한기후 분석을 위하여 $\mathrm{WMO}$ 가 제시한 Expert Team on Climate Change Detection and Indices (ETTCCDI)에서 27개의 지수 중 기후와 가장 밀접하게 관련 있는 8개의 지수를 사용하였다. 분석을 위하여 과거와 미래로 구분하였으며, 과거의 자료는 1991년 2019년, 미래는 RCP 8.5 기후변화 시나리오 자료를 이용하여 2020년 2100년까지 분석을 실시하였다. 극한기후 분석 결과, 과거 경향을 보았을 때 제주관측소에서 일 최고기온이 $25{ }^{\circ} \mathrm{C}$ 이상인 일 수를 보여주는 폭염 일수가 제주지역은 지속적으로 증가하는 경향을 보였으며, $0{ }^{\circ} \mathrm{C}$ 미만의 일 수를 보여주는 서리일수에서는 1996년 성산 지역에서 40 일이 넘어 세 곳의 지역 중 가장 많은 날을 보여주고 있다. 기후변화시나리오를 적용한 결과 폭염 일수는 세 곳(제주, 서귀포, 성산)에서 상승추세의 그래프가 나타났으며, 서리 일수는 21 세기 후반으로 진행 될수록 $0{ }^{\circ} \mathrm{C}$ 에 수렴하는 일 수가 0 에 수렴 하는 것을 확인 하였다. 일 최고 기온의 그래프에서는 다른 지역에 비해 제주지역이 $40{ }^{\circ} \mathrm{C}$ 가 넘는 그래프가 많은 것을 확인 하였다. 본 연구를 통하여 관측소 별로 기후특성을 고려하여 도시계획 및 방재대책을 세워야 한다고 판단된다.

핵심용어 : 제주도, 기후변화, ETCCDI, 기후변화시나리오

*정회원, 국립강원대학교 방재전문대학원 도시·환경재난관리전공 석사과정(E-mail: sr7895@kangwon.ac.kr)

Member, Master's Course, Dept. of Urban Environment \& Disaster Prevention school of Disaster Prevention, Kangwon National University

**정회원, 국립강원종합기술연구원 토양·기후 환경 연구센터 선임연구원(E-mail: climate@kangwon.ac.kr)

Member, Senior Researcher, Soil and Climate Environmental Research Center of the Gangwon Institute of Technology

***교신저자, 정회원, 국립강원대학교 방재전문대학원 도시 - 환경재난관리전공 정교수(Tel: +82-33-570-6819, Fax: +82-33-570-6458,

E-mail: hydrokbs@kangwon.ac.kr)

Corresponding Author, Member, Professor, Dept. of Urban Environment \& Disaster Management, Kangwon National University 


\section{1. 서 론}

최근 지구온난화로 인한 기후시스템이 인간에 미치는 부정적인 영향이 계속해서 늘어나고 있다. 지구온난화의 주된 이유로 빙하의 감소로 인한 평균 해수면 상승, 대기와 해양의 온난화, 해양의 산성화 등의 가능성이 가장 높다. 이로 인한 생태계 악화, 경제손실과 인명피해를 일으키고 있으며, 극한기후, 이상기후의 빈도와 강도 또한 증가하고 있다. 지구의 평균기온은 지난 100 년 동안 $0.78^{\circ} \mathrm{C}$ 가 증가하 였으며(IPCC, 2014), 제주도의 기온도 1961년부터 2019년 까지 10 년 동안 $0.3{ }^{\circ} \mathrm{C} / 10$ 년 증가하였다(Seo, 2013).

기후변화가 심화됨에 따라 극한기후에 관련된 연구가 활발히 진행 되고 있으며, 대표적인 연구사례를 찾아보면 다음과 같다. Kim et al. (2011)은 미래의 가뭄 변동성을 분석하기 위해 표준강수지수(SPI)를 산정하였고, 2045년대 와 2075년대에서 강수량 감소로 인하여 내륙의 가뭄 출현 빈도가 증가 할 것이라고 전망하였다. Jeung et al. (2019)은 2011년부터 2100년까지 분석 기간 동안 한반도 중부지역의 극한강우 및 이상기온현상의 발생빈도가 증가할 것으로 전망하였으며, 또한 미래 한반도의 극한강우 및 이상기온현 상의 빈도와 규모 증가 할 것으로 분석하였다. Ahn et al. (2011)은 전 지구의 이산화탄소 평균 농도인 $1.9 \mathrm{ppm} \mathrm{yr}^{-1}$ 에 비하여 한반도의 이산화탄소 평균 농도가 탄력적으로 증가 하고 있으며, 한반도의 혹한 기온은 차츰 낮아지고 혹서 기온은 차츰 증가함에 따라 평균 기온의 상승을 유도할 것으로 평가하였다. Kim and Choi (2010)은 제주도 기온관련 미래 극한기후지수 중 열대야율, 폭염지속일수가 모든 지점 에서 증가할 것으로 전망하였고, 그 중 $10 \mathrm{~mm}$ 이상 강수일수, 5 일 최대강수량, 95 퍼센타일 호우율은 서귀포에서 특히 증 가하여 다른 지역에 비하여 피해가 클 것으로 예측하였다. Seo (2013)은 Mann-Kendall 검정기법을 이용하여 제주, 서 귀포, 성산, 고산의 경향을 분석한 결과, 기온 및 강수량은 모두 증가하는 전망을 보이나 최근 10 년간의 추세를 보았을 때 연구 관측 지점의 기온이 하강하는 경향이 나타나는 것으 로 분석하였다. Kim and Kim (2009)은 극한지수를 이용하여 한반도의 강우 관련 극한지수를 분석하였으며 그 결과 강우 량 비율과 발생빈도는 여름철에 대체적으로 동서 방향으로 내륙전반에 걸쳐 증가하는 경향을 확인하였다. 또한 $\mathrm{Kim}$ et al. (2008)은 기상청 산하 66개의 기상관측소의 일 강우량 과 일 최고 온도, 일 최소 온도를 사용하여 강우와 기온관련 극한지수를 제시하였다. 강우의 경우 여름철에 중부지방을 중심으로 집중호우가 발생되는 비율의 경향성과 지속기간 5 일 최대 강수량이 두드러지게 증가하는 것을 분석하였으며, 기온의 경우 제주도와 남해 부근에서는 겨울철에 비해 여름 철에 기온 상승경향이 뚜렷하다는 것을 확인하였으며, 따라 서 우리나라의 비정상적인 기후 출현 가능성이 증가한다는 것을 확인하였다.
제주도는 세계자연유산으로써 매년 약 1,000 만 명이 방문 하는 한국 최대의 관광지이다. 그러나 현재 제주도의 연 평균기온이 10 년마다 $0.29{ }^{\circ} \mathrm{C}$ 씩 상승하였으며, 극한기후 발생빈도가 빈번해지고 강도가 강해지는 모습을 보이고 있다. 제주도는 관광적, 경제적으로 높은 가치로 존재하고 있지만 제주도에 관한 기후변화 연구가 내륙지역에 비해 미비하여 폭염과 폭설과 같은 자연재해에 취약한 모습을 보여주고 있으며, 이러한 환경 때문에 관광적 또는 경제적으 로 타격을 입어 가치가 감소되지 않도록 많은 관심과 연구가 필요하다.

본 논문에서는 과거와 미래의 강우자료와 기온자료를 이용하여, ETCCDI 극한지수 분석을 통해 극한기후의 강도 와 빈도에 대하여 분석하였다. 연구지역인 제주도는 해양성 기후에 크게 영향을 받고 있으며, 이는 기후변화와 상관성이 매우 크다. 또한 제주도의 면적은 $1,849 \mathrm{~km}^{2}$ 로 서울의 세 배이며, 해발 $1,949.2 \mathrm{~m}$ 인 한라산을 기준으로 4 개소의 관측 지점이 서로 다른 기후를 보이고 있어, 타 지역에서 볼 수 없는 특수한 기후현상을 볼 수 있다. 또한 한라산에 의한 푄현상이 빈번히 나타나기 때문에 기후변화에 매우 민감하 지만, 현재 제주도에 관한 선행연구가 육지에 비해 부족하다.

이에 본 논문에서는 과거에서 현재까지 제주도 3 개소의 관측소에서 어떠한 모습으로 기후와 빈도가 발생했는지 분석 하기 위해, $\mathrm{WMO}$ 에서 제시한 Expert Team on Climate Change Detecsion and Indices (ETCCDI)지수를 이용하였고, 또한 분석기간의 자료를 동일하게 하기 위해 1990년대 이후 극한 사상 변화를 분석하였다.

\section{ETCCDI 극한지수}

기후변화의 원인으로 지구온난화, 도시화, 무분별한 벌목 등 다양한 이유가 있으며, EU에서는 기후변화의 양상과 빈도를 파악하기 위해 극한지수(STARDEX) 프로젝트를 수용하였다. 이는 통계적, 동적 및 역학적 축소기법으로 강우 관련지수와 기온관련 지수를 이용하여 극한지수를 산정할 수 있고, 결과적으로 미래극한기후사상을 추론 할 수 있다.

세계기상기구(World Meteorological Organization, WMO) 는 관측된 자료를 가지고 미래 극한기후의 변화와 극치지수를 정의 할 수 있게 ETCDCDI 극한지수(Expert Team on Climate Charge Detecsion and Indices, ETCCDI)를 정의하였다. ETCCDI 극한지수는 총 27 개이며, 그 중 강수관련 극한지수는 11 개, 기온관련 극한지수 16 개로 구성되어 있다.

본 연구에서 연구대상의 과거와 미래의 극한사상을 정량 화하기 위해 $\mathrm{WMO}$ 에서 제시한 27개의 ETCCDI지수(Expert Team on Climate Charge Detecsion and Indices, ETCCDI) 중 기후와 밀접한 관계가 있는 기온 관련 항목 4개(SU, FD, $\mathrm{TXx}, \mathrm{TNn})$ 와 강수 관련 항목 4개(PRCPTOT, RX1day, R10mm, $\mathrm{R} 20 \mathrm{~mm}$ )를 이용하였다. 각 항목에 관한 설명을 나타낸 
Table 1 에서 기온관련 항목 중 SU25는 일 최고기온이 $25{ }^{\circ} \mathrm{C}$ 가 넘는 날짜의 수를 의미하며, $\mathrm{FD} 0$ 는 일 최저기온이 $0{ }^{\circ} \mathrm{C}$ 보다 낮은 날짜의 수를 나타내고 있다. TXx는 일 최고기온을 의미하며, $\mathrm{TNn}$ 은 일 최저기온을 의미하고 있다. 강우관련 항목에서 PRCPTOT는 연 총강우량을 의미하며, RX1day는 월 별 최대 1 일 강우량을 의미한다. R $10 \mathrm{~mm}$ 는 강우가 $10 \mathrm{~mm}$ 이상 온 날짜의 수를 의미하며, R20mm는 강우가 $20 \mathrm{~mm}$ 이상 온 날짜의 수를 의미한다.

\section{3. 연구 자료}

제주도 내 관측소는 3 개소의 종관기상관측소(ASOS)와 35 개소의 방재기상관측소(AWS)가 운영 중이며, 본 논문에 서는 관측소의 종관기상관측소와 방재기상관측소의 정량적 데이터를 이용해야 하지만 부속도서에 속해있거나 관측시
기가 짧은 $\mathrm{AWS}$ 를 제외하였고, 3 개소의 기상관측소의 정량 적 데이터를 가지고 분석을 하였다.

Fig. 1 의 지점은 기상관측소의 위치를 나타낸 것이며, 지점 들이 제주, 서귀포, 성산의 기후를 통하여 제주도의 대표되는 기후값을 측정할 수 있다.

30 년간 연평균 강우량은 제주는 $1,497 \mathrm{~mm}$, 서귀포는 1,923 $\mathrm{mm}$ 이며 성산은 $1,966 \mathrm{~mm}$ 이다. 해양성 기후인 제주도에서 는 3 개소의 기상관측소가 강수의 패턴이 상이하게 나타나기 때문에, 해안가를 근접하는 곳에 기상관측소가 위치하고 있으며, Table 2 를 보게 되면 제주도가 고도에 따른 강우량 편차가 매우 큰 지역이기 때문에 3 개소의 기상관측소가 해발 $100 \mathrm{~m}$ 이하에 위치하여 있다. 관측기간을 보게 되면 제주의 기상관측소의 관측기간이 1923년으로 가장 길며, 나머지 두 지역(서귀포, 성산)보다 정확한 자료를 추출 할 수 있다는 장점을 가지고 있다.

Table 1. ETCCDI Indices Used in This Study

\begin{tabular}{|c|c|c|c|}
\hline Categorization & ID & Descrption & Unit \\
\hline \multirow{4}{*}{ Temperature } & SU25 & Summer day, TMAX $>25{ }^{\circ} \mathrm{C}$ & Day \\
\hline & FD0 & Frost days $\mathrm{TMIN}<0{ }^{\circ} \mathrm{C}$ & Day \\
\hline & TXx & Max TMAX & ${ }^{\circ} \mathrm{C}$ \\
\hline & $\mathrm{TNn}$ & Min TMIN & ${ }^{\circ} \mathrm{C}$ \\
\hline \multirow{4}{*}{ Precipitation } & PRCPTOT & Annual total PRCP in wet days (daily PRCP) $\geq 1 \mathrm{~mm}$ & $\mathrm{~mm}$ \\
\hline & RX1day & Monthlymaximum 1-day precipitation & $\mathrm{mm}$ \\
\hline & $\mathrm{R} 10 \mathrm{~mm}$ & Annual count of days when PRCP $\geq 10 \mathrm{~mm}$ & Day \\
\hline & $\mathrm{R} 20 \mathrm{~mm}$ & Annual count of days when PRCP $\geq 20 \mathrm{~mm}$ & Day \\
\hline
\end{tabular}

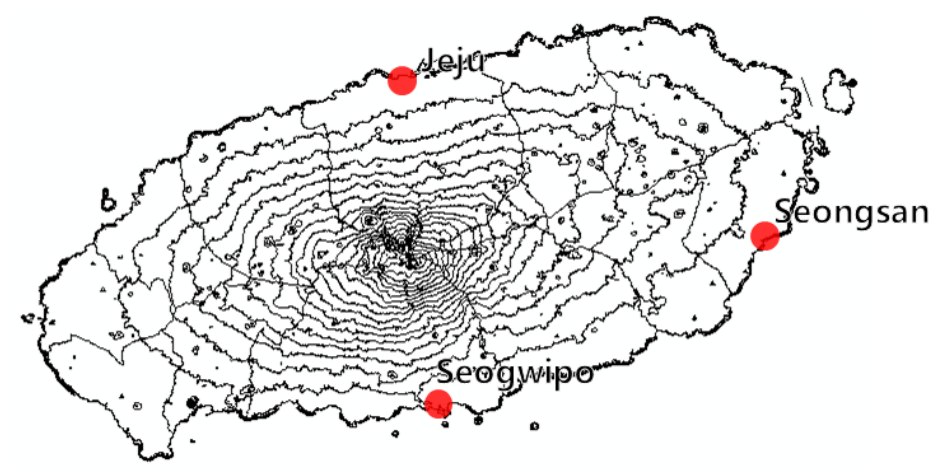

Fig. 1. Location of Weather Stations

Table 2. Information of Weather Stations

\begin{tabular}{c|c|c|c|c|c}
\hline Station & Latitude & Longitude & Above sea level (m) & $\begin{array}{c}\text { Observation } \\
\text { commencement year (yr) }\end{array}$ & Period (yr) \\
\hline Jeju & $33^{\circ} 31^{\prime}$ & $126^{\circ} 32^{\prime}$ & 20.0 & 1923 & $1961 \sim 2020$ \\
\hline Seogwipo & $33^{\circ} 15^{\prime}$ & $126^{\circ} 34^{\prime}$ & 50.5 & 1961 & $1961 \sim 2020$ \\
\hline Seongsan & $33^{\circ} 23^{\prime}$ & $126^{\circ} 53^{\prime}$ & 18.6 & 1973 & $1973 \sim 2020$ \\
\hline
\end{tabular}


본 연구에서는 3 개의 해당 관측소의 관측 자료를 대상으로 1991년 2000년을 Current 1, 2001년 2010년을 Current 2, 2011년 2019년을 Current 3으로 시간적 범위를 나누었고, 미래기후시나리오 RCP 8.5를 적용하여 2020년 2040년을 Future 1, 2041년 2070년을 Future 2, 2071년 2100년을 Future 3 으로 시간적 범위를 나누었다. 분석결과는 시계열 자료로 작성하였고, 관측 자료의 자료기준은 $\mathrm{ETCCDI}$ 지수 를 이용하여 제주도의 극한 기후사상에 대하여 분석하였다.

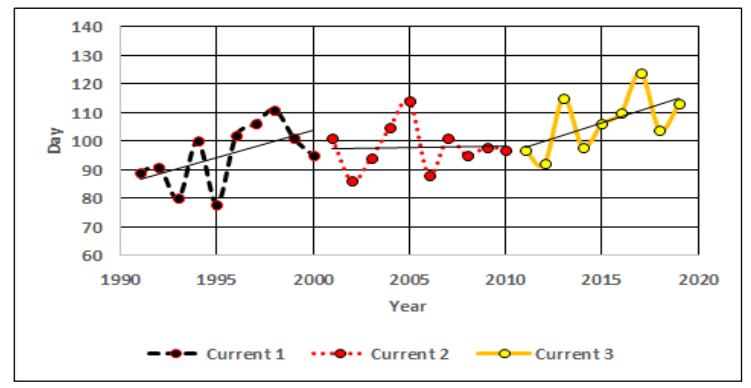

(a) Summer day (SU25)

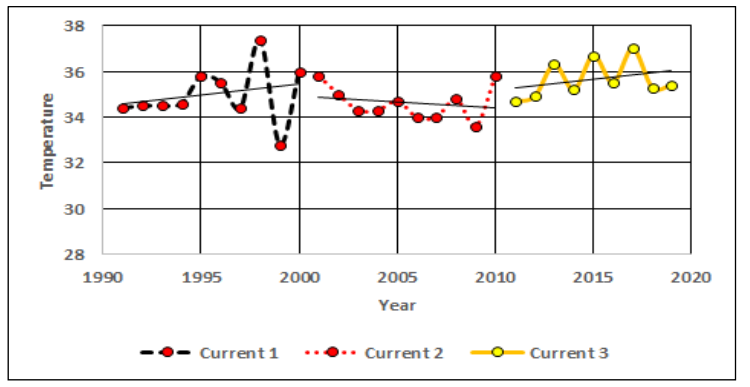

(c) Max TMAX (TXx)

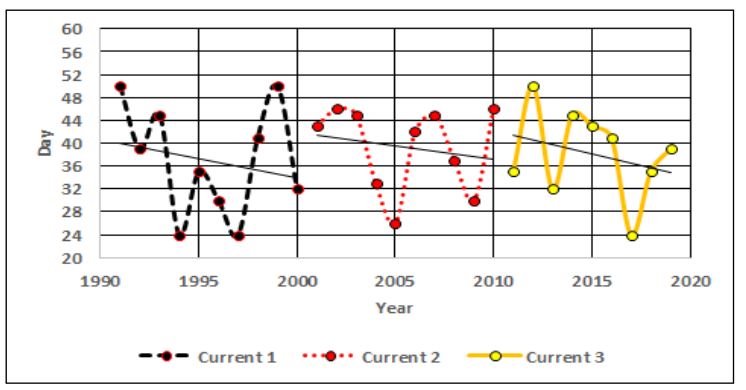

(e) Annual count of days when PRCP $\geq 10 \mathrm{~mm}$ (R10mm)

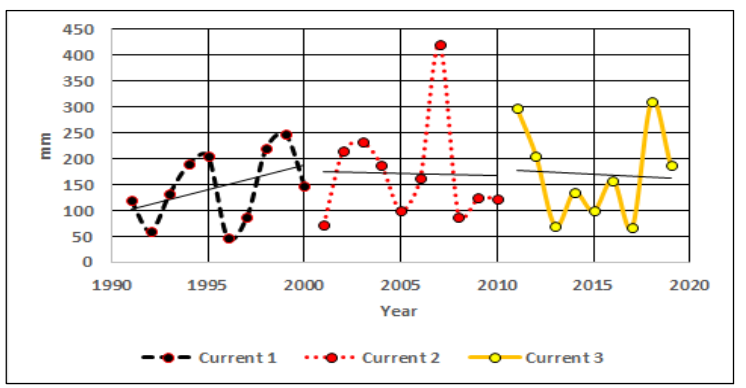

(g) Max 1-day precipitation (RX1day)

\section{4. 제주지역의 ETCCDI 분석}

\section{1 과거자료(30년)를 이용한 분석}

제주의 Current 기간 동안의 과거 경향은 다음과 같다. 기온관련지수 중 폭염 일수(Fig. 2(a))의 Current 1 (1990 2000) 과 Current 3 (2010 2019)에서 상승추세선을 보여주어 과거 30 년 동안 폭염일수가 증가하는 것으로 분석되었다. 일 최고 기온(Fig. 2(c))를 보면 Current 1기간과 Current 3 기간이

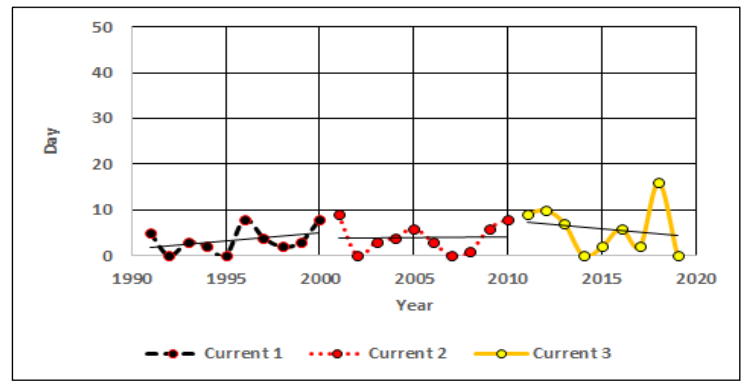

(b) Frost days (FD0)

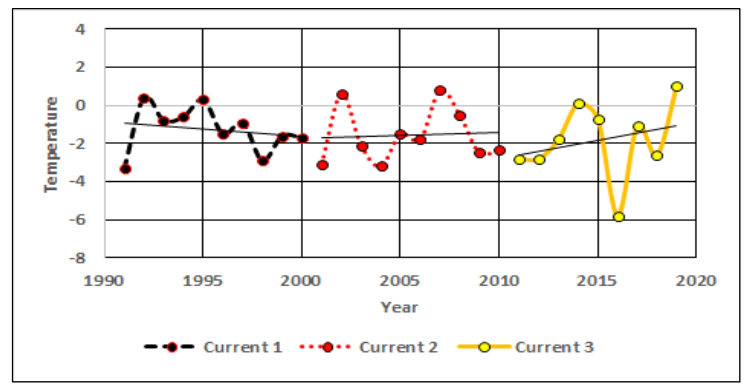

(d) Min TMIN (TNn)

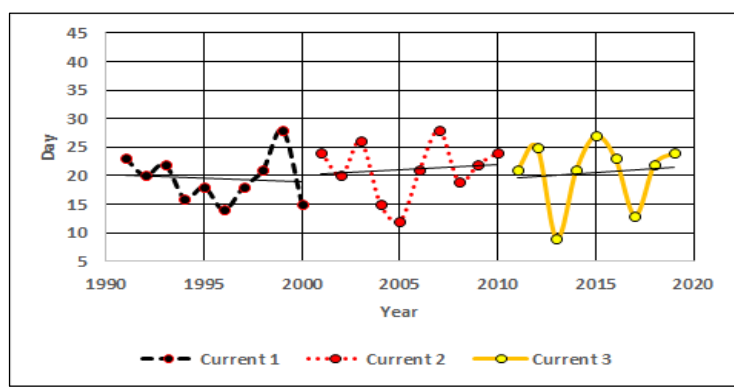

(f) Annual count of days when PRCP $\geq 20 \mathrm{~mm}$ (R20mm)

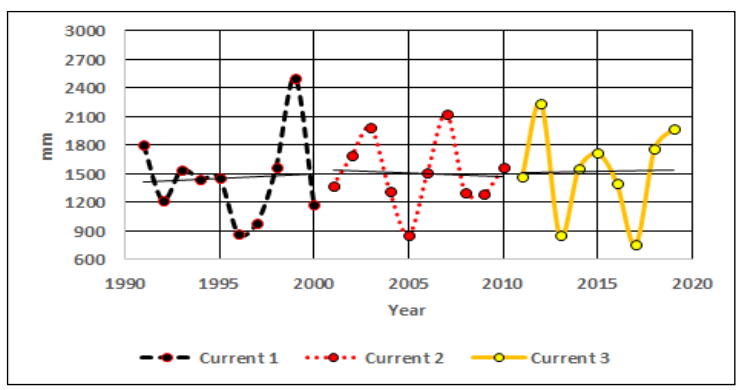

(h) Annual total PRCP in wet days (PRCPTOT)

Fig. 2. Indicate a Time-Series Change of the ETCCDI Index (Jeju) 
상승추세선을 보여주며, 폭염 일수(Fig. 2(a))와 비슷한 추세 의 양상을 확인 할 수 있다. 폭염 일수와 일 최고기온을 확인 한 결과 과거 30 년 동안 제주의 지역에서는 $25{ }^{\circ} \mathrm{C}$ 가 넘는 폭염 일수가 증가하고 있으며, 일 최고기온도 따라 증가하는 경향을 보여주고 있다. 반면 서리 일수(Fig. 2(b))의 Current 3 기간에서 하락추세선을 보여주는 모습을 보이고 있으며, 일 최저기온(Fig. 2(d))의 경우 Current 3에서 상승경 향을 보여주어 일 최저온도가 $0{ }^{\circ} \mathrm{C}$ 에 가까워지는 경향을 보였다.

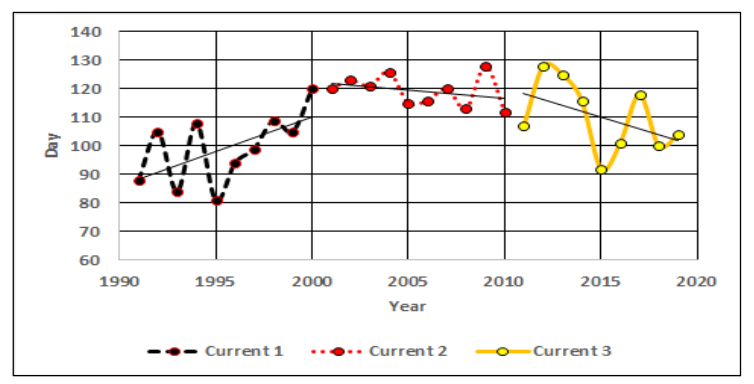

(a) Summer day (SU25)

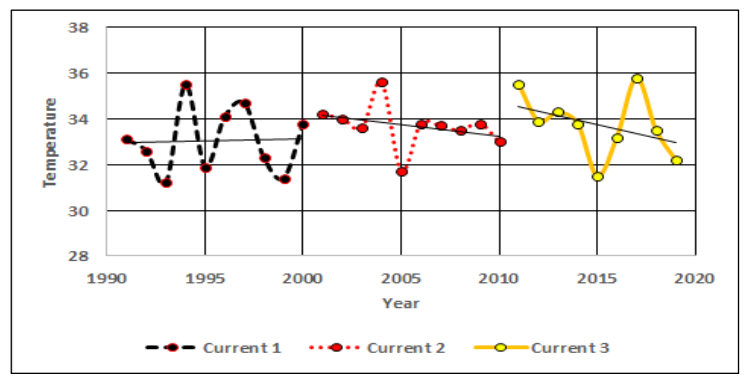

(c) Max TMAX (TXx)

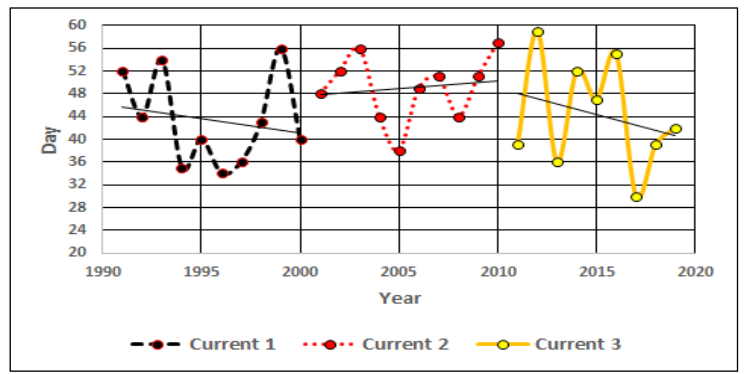

(e) Annual count of days when PRCP $\geq 10 \mathrm{~mm}$ (R10mm)

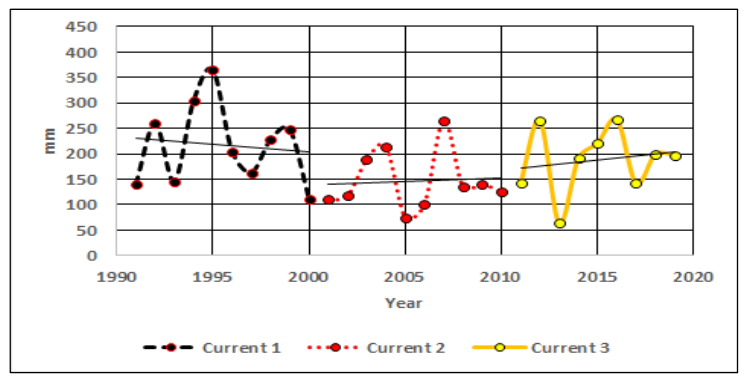

(g) Max 1-day precipitation (RX1day)
강수관련지수인 R10mm (Fig. 2(e))와 R20mm (Fig. 2(f)) 는 강우가 $10 \mathrm{~mm}, 20 \mathrm{~mm}$ 이상 온 날의 수를 나타내고 있다. 1990년, 1999년, 2012년에 $10 \mathrm{~mm}$ 이상 온 날의 수가 50 일 이상으로 가장 많았지만, R20mm에 비교하면 강우의 양이 차이가 난다는 것을 보여주고 있다. 이는 $10 \mathrm{~mm}$ 이상 강우는 많이 내렸지만, $20 \mathrm{~mm}$ 가 넘는 강우는 오지 않았음을 확인 할 수 있다.

서귀포의 경우 기온관련지수 중 폭염 일수(Fig. 3(a))에서 는 Current 1 (1990 2000)기간 동안 상승경향을 보여주었지

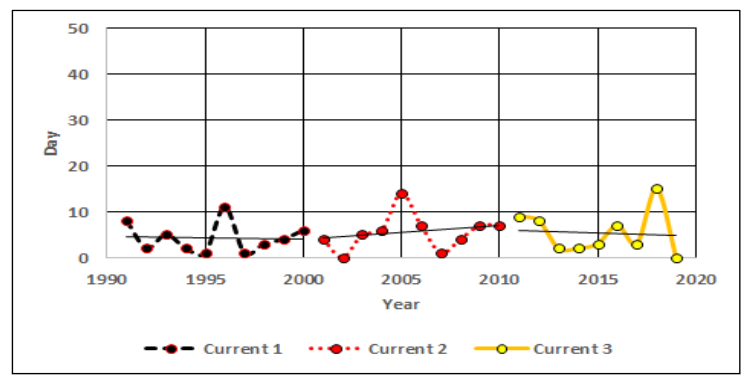

(b) Frost days (FD0)

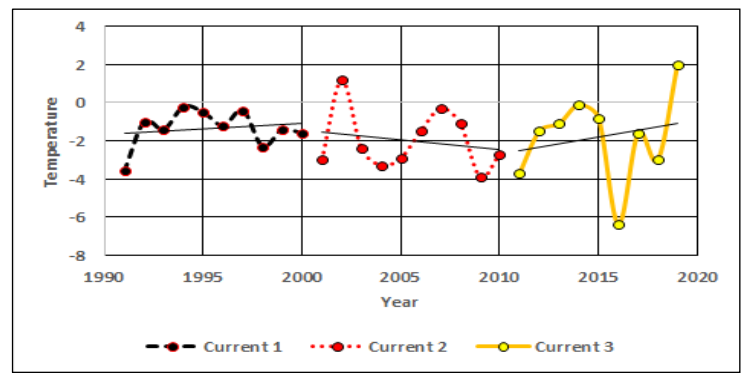

(d) Min TMIN (TNn)

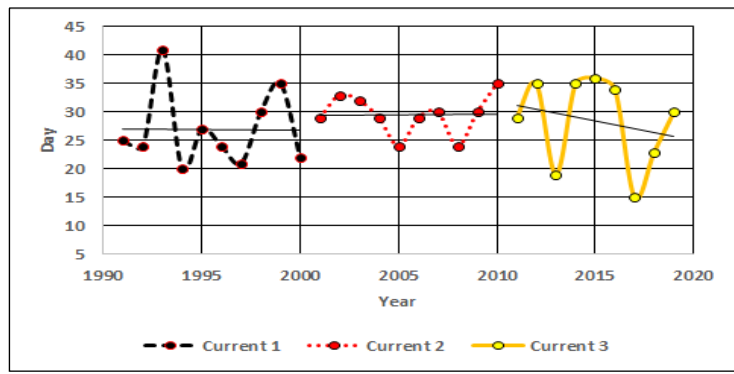

(f) Annual count of days when PRCP $\geq 20 \mathrm{~mm}$ (R20mm)

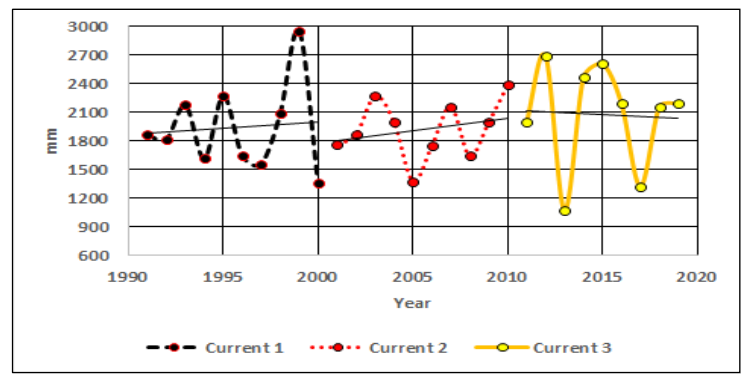

(h) Annual total PRCP in wet days (PRCPTOT)

Fig. 3. Indicate a Time-series Change of the ETCCDI Index (Seogwipo) 
만, 반대로 Current 2 (2000 2010), Current 3 (2010 2019) 기간 동안에는 하락경향그래프를 보여주고 있다. 일 최고기 온(Fig. 3(c))은 Current 1에서는 완만한 경향의 모습을 보여 주고 있었으나, Current 2 와 Current 3 에서 하락경향의 모습 을 확인 할 수 있다. 강수발생일수인 R10mm (Fig. 3(e))와 $20 \mathrm{~mm}$ (Fig. 3(f))의 Current 3기간 동안 공통적으로 하락추세 의 그래프를 보여주었으며, 총 강수량(Fig. 3(h))에서는 2013 년과 2017년의 강수가 가장 낮은 모습을 보여주고 있다.
성산의 Current 기간 동안의 경향은 다음과 같다. 기온관련 지수 인 폭염 일수(Fig. 4(a))에서 Current 1 (1990 2000) 기간 동안 상승경향을 보여주어, $25{ }^{\circ} \mathrm{C}$ 가 넘는 폭염일수가 많아졌음을 확인 할 수 있었고, 일 최고기온(Fig. 4(c))을 나타내는 그림에서는 Current 2 기간 동안 최고기온이 낮아 지는 하락경향을 보이다가, Current 3에서 반대로 상승경향 의 모습을 확인 할 수 있었다. 또한 여기서 폭염 일수와 일 최고기온이 비슷한 추세가 나타났음을 확인 할 수 있었으

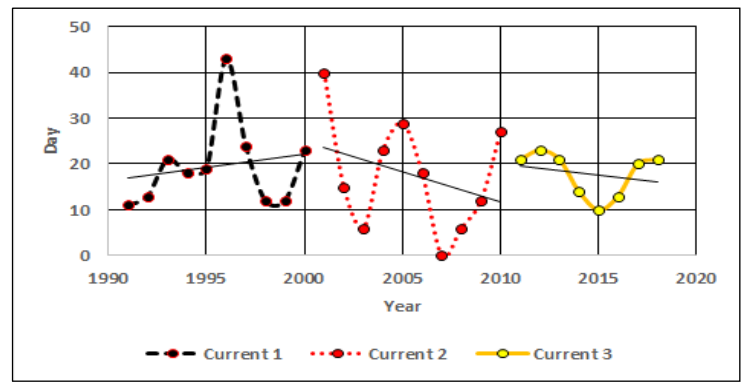

(b) Frost days (FD0)

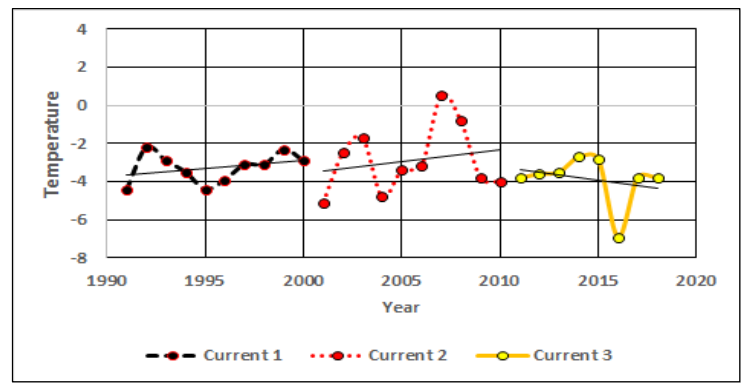

(d) Min TMIN (TNn)

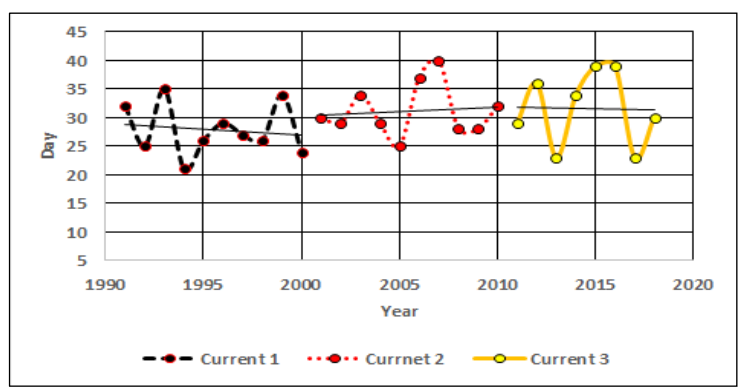

(f) Annual count of days when PRCP $\geq 20 \mathrm{~mm}$ (R20mm)

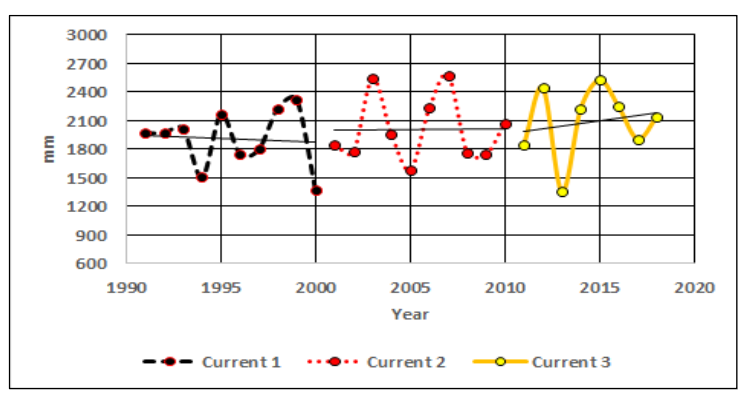

(h) Annual total PRCP in wet days (PRCPTOT)

(g) Max 1-day precipitation (RX1day)

Fig. 4. Indicate a Time-series Change of the ETCCDI Index (Seongsan) 
며, 이는 폭염일수와 일 최고기온이 증가 추세가 나타나고 있다는 것을 알 수 있다.

\section{2 기후변화시나리오를 이용한 분석}

제주지역에서의 폭염 일수(Fig. 5(a))에서 Future 기간 동 안 상향추세의 모습을 나타내었으며, 그 중 Future 2에서 가장 큰 상승추세의 모습을 보여주었다. 서리 일수(Fig. 5(b))

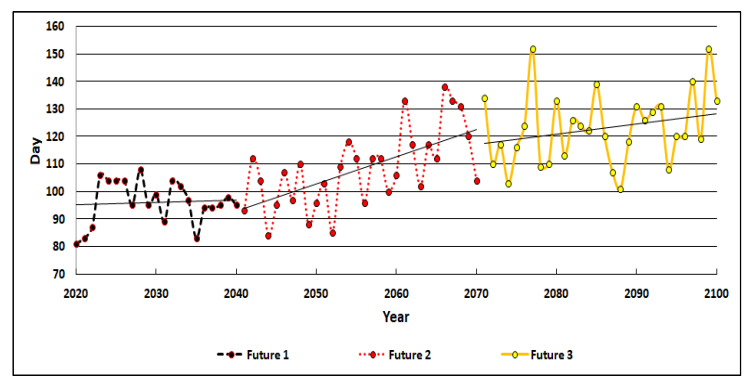

(a) Summer day (SU25)_Jeju

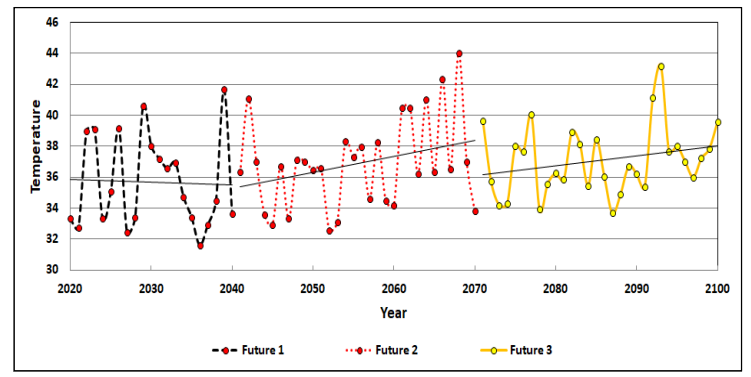

(c) Max TMAX (TXx)_Jeju

Fig. 5. ETCCDI Index with Climate Change Scenario (Jeju)

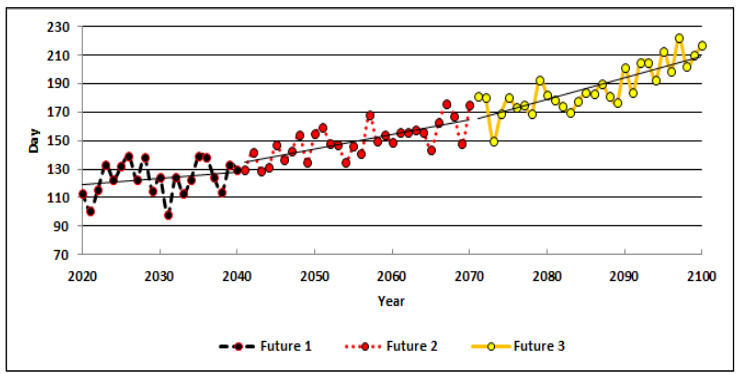

(a) Summer day (SU25)_Seoguipo

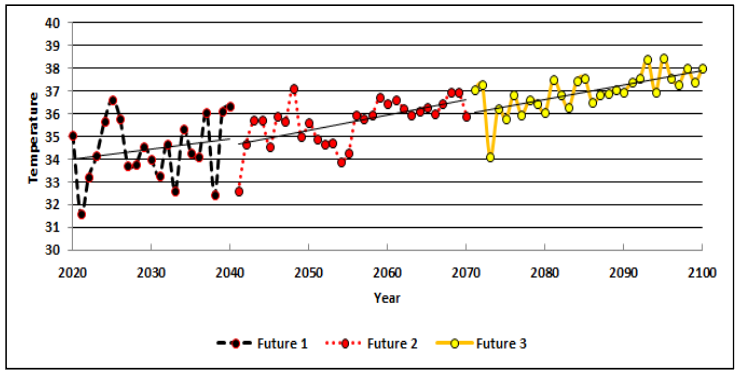

(c) Max TMAX (TXX)_Seoguipo
는 지속적으로 감소하는 경향을 나타냈으며, 지구온난화로 인한 최저기온이 $0{ }^{\circ} \mathrm{C}$ 넘는 일 수가 0 에 수렴한다는 것을 확인하였다. 또한 일 최고 기온(Fig. 5(c))에서는 폭염 일수와 같이 상승경향의 모습을 보여주며 일 최고기온이 $40{ }^{\circ} \mathrm{C}$ 가 넘는 날이 가장 많은 것으로 확인되었다.

서귀포 지역에서는 폭염 일수(Fig. 6(a))가 Future 3에서 220 일이 넘는 모습을 보여주며, 세 관측소 중 가장 많은

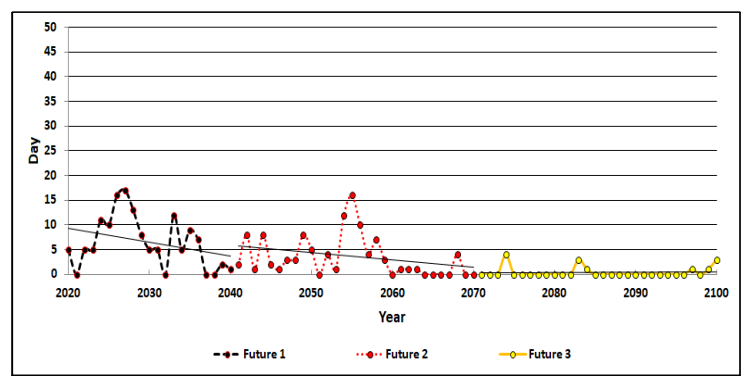

(b) Frost days (FD0)_Jeju

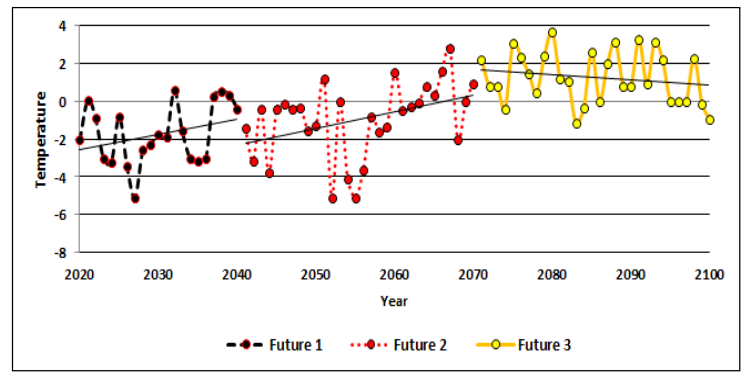

(d) Min TMIN (TNn)_Jeju

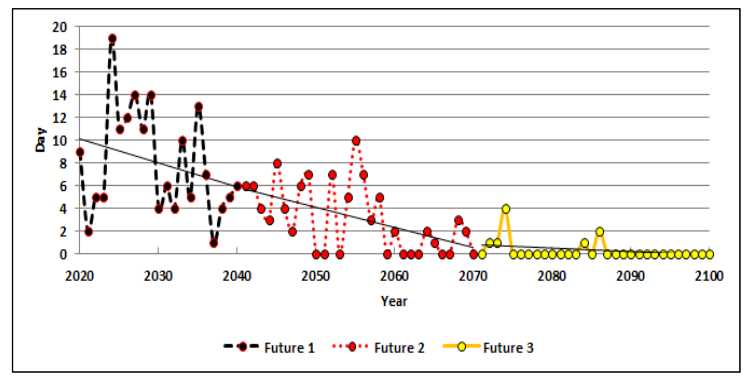

(b) Frost days (FD0)_Seoguipo

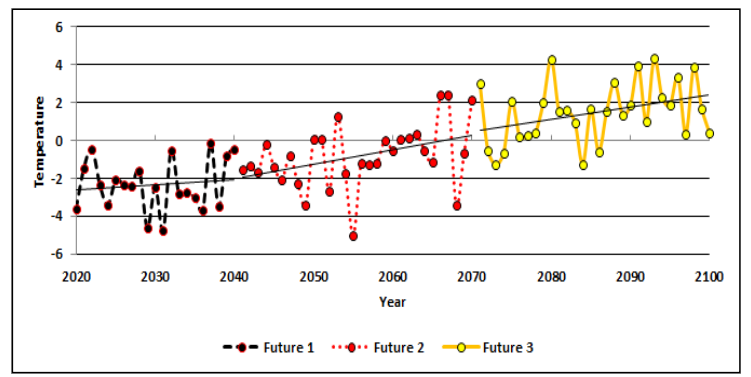

(d) Min TMIN (TNn)_Seoguipo

Fig. 6. ETCCDI Index with Climate Change Scenario (Seoguipo) 


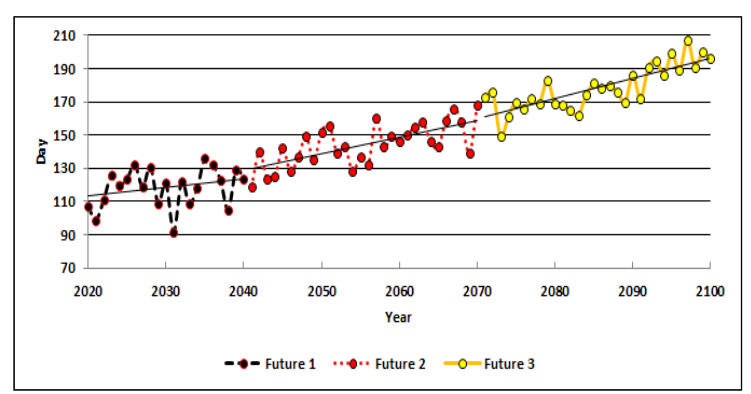

(a) Summer day (SU25)_Seongsan

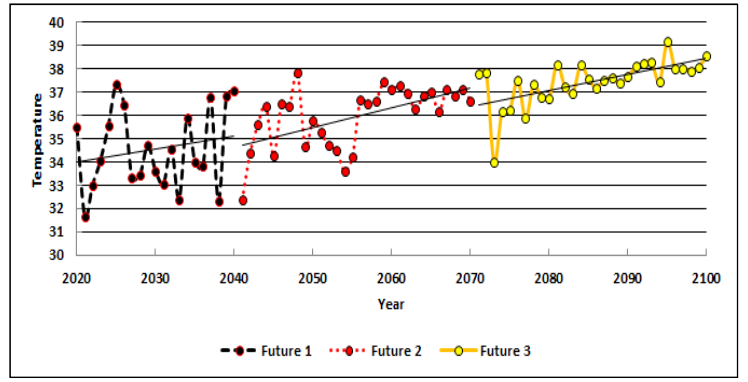

(c) Max TMAX (TXx)_Seongsan

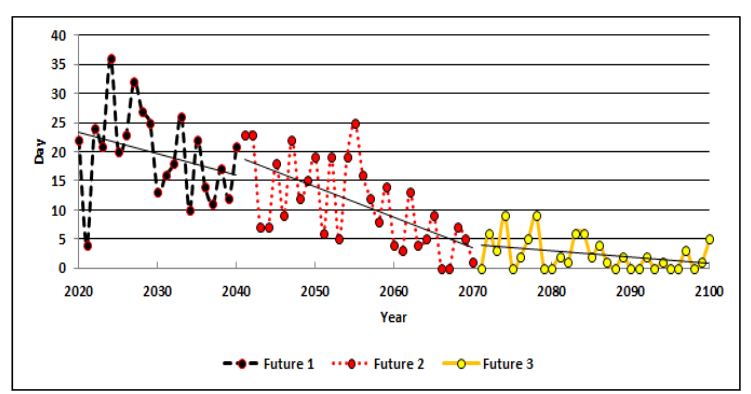

(b) Frost days (FD0)_Seongsan

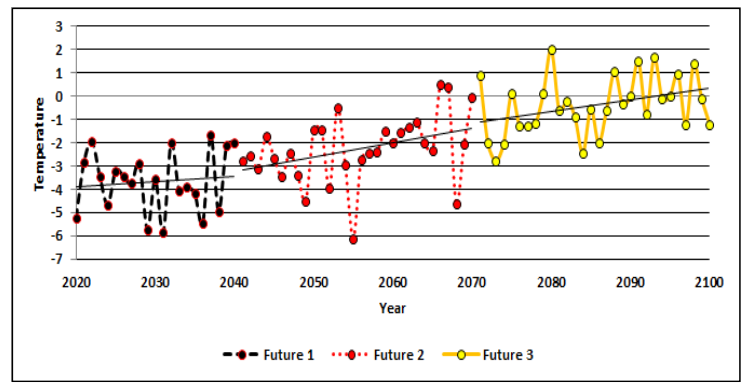

(d) Min TMIN (TNn)_Seongsan

Fig. 7. ETCCDI Index with Climate Change Scenario (Seongsan)

폭염 일수가 나타난 다는 것을 확인하였다. 또한 기온관련 지수인 일 최저기온(Fig. 6(b))에서는 $0{ }^{\circ} \mathrm{C}$ 를 넘어 $4{ }^{\circ} \mathrm{C}$ 에 가까워지며, 다른 두 곳보다 온난한 겨울이 나타나는 것이 확인된다.

성산 지역의 Future 1에서 기온관련 지수인 서리 일수(Fig. 7(b))가 다른 지역에 비해 많은 날을 보여주고 있지만, Future 2 기간부터 감소경향이 크게 나타나는 것을 확인하였으며, 성산지역의 일 최고기온(Fig. 7(c))이 서귀포 지역의 양상과 비슷한 추세로 나타나는 것을 확인하였다.

\section{4. 결 론}

제주도는 해양성 기후에 영향을 받으며, 기후변화와 상관 성이 매우 큰 지역이면서 기후변화에 민감하지만, 기후변화 에 대한 선행연구가 내륙에 비해 부족하여 분석지역으로 선정하였다. 극한기후를 분석하기 위하여, 3 개소의 기상관 측소(제주, 서귀포, 성산)의 자료를 이용하였으며, 분석방법 은 3개소의 기상관측소의 과거자료(1990 2019)와 기후변화 시나리오의 네 가지 방법 중 RCP 8.5 를 ETCCDI 지수에 적용하 여 대표적인 온도관련지수 4 가지(SU25, $\mathrm{FD} 0, \mathrm{TXx}, \mathrm{TNn})$ 와 강우관련지수 4가지(R10mm, R20mm, RX1day, PRCPTOT) 를 분석하였으며, 분석결과는 시계열 그래프로 나타내었다. 분석결과의 요약 및 결론은 다음과 같다.

1) 과거자료 30년(1990 2019)을 적용한 결과 기온관련지 수 중 폭염 일수(SU25)의 경우 제주지역은 나머지 세 곳의 지역과는 달리 Current 기간 동안 지속적으로 상향
추세의 그래프를 나타내었으며, 일 최고기온(TXx)도 폭염 일수와 비슷한 양상으로 상향추세의 그래프가 나타난 것을 확인하였다. $0{ }^{\circ} \mathrm{C}$ 미만의 일(day)수를 나타 내는 서리일수(FD0)에서 성산 지역이 1996년에 40일 이 넘는 것으로 나타났고, $0{ }^{\circ} \mathrm{C}$ 미만의 일(day)수가 다른 세 곳의 기상관측소 보다 가장 많은 것으로 확인 되었다. 일 최저기온(TNn)에서는 성산을 제외한 나머 지 세 곳이 최근 기간(2011 2019)동안 상승추세의 그 래프가 확인이 되었으며, 성산지역은 최근기간인 Current 3에서 감소추세의 그래프가 나타났다. 강우관 련지수인 총 강수량(PRCPTOT)에서는 3 개소의 관측 소에서 유사한 모습의 그래프가 나타난 것을 확인 할 수 있다. 또한 제주지역의 경우 일 강우량이 $10 \mathrm{~mm}$ 이상을 나타내는 지수인 R10mm에서 Current 기간 동 안 감소추세의 그래프가 나타낸 반면, $\mathrm{R} 20 \mathrm{~mm}$ 에서는 추세의 변화가 없는 것으로 나타났고, 나머지 세 지역은 $\mathrm{R} 10 \mathrm{~mm}$ 와 R20mm의 추세가 비슷한 양상을 나타내고 있다.

2) 미래 극한의 상황에서의 기후분석을 위하여 RCP8.5 기후변화 시나리오를 사용하였으며, Future 1 (2020 년 2040년), Future 2 (2041년 2070년), Future 3 (2071 년 2100년)으로 기간을 구분하여 각 기간별 기후특성 에 대해서 분석하고자 하였다. 적용 결과 기온관련지수 중 폭염일수(SU25)에서 세 곳(제주, 서귀포, 성산)에서 상승추세의 모습을 공통적으로 보여주고 있으며, 그 중 서귀포지역에서 220 일로 가장 많은 폭염일수가 
확인 되었다. 서리 일수(FD0)에서는 세 곳(제주, 서귀 포, 성산)의 지역이 공통적으로 감소하는 경향이 나타 났으며, 세 지역 중 성산 Future 1기간의 서리일수가 가장 많았으나, 크게 감소하는 경향을 보여주고 있다. 결국 세 지역의 공통적인 모습으로, 21 세기 후반인 Future 3 에서 $0{ }^{\circ} \mathrm{C}$ 에 수렴하는 일(day)수가 0 에 수렴하 는 것을 확인하였고, 저온관련현상이 감소 될 것으로 전망하였다. 일 최고기온(TXx)에서는 세 곳의 그래프 가 상승추세의 모습이 나타났으며, 그 중 제주지역은 일 최고기온이 $40{ }^{\circ} \mathrm{C}$ 가 넘는 빈도가 다른지역에 비해 많음을 확인하였다.

본 연구에서는 과거자료와 기후변화시나리오 자료를 이 용하여 연구지역인 제주도의 극한사상을 분석하였으며, 지 구온난화로 인한 발생할 수 있는 극한기후사상의 분석은 인명 및 사회구조의 피해를 저감하기 위한 기초적인 자료로 활용 될 수 있으며, 추후 구조적-비구조적 대책 마련을 위한 자료로 사용 될 것이라 판단된다.

\section{감사의 글}

이 연구는 기상청 기상영향 연구 및 영향예보 생산기술 개발 사업(KMI 2021-00312)의 지원으로 수행되었습니다.

\section{References}

Ahn, S.I., Ha, K.J., Seo, K.H., Yeh, S.W., Min, S.K., and Ho, C.H. (2011). A review of recent climate trends and causes over the Korean peninsula. Climate Change Research, Vol. 2, No. 4, pp. 237-251.

IPCC. (2014). Climate Change 2014: Synthesis Report. Contribution of Working Groups I, II and III to the
Fifth Assessment Report of the Intergovernmental Panel on Climate Change.

Jeung, S.J., Park, J.Y., Yang, D.M., and Kim, B.S. (2019). The future of extreme climate change in the Korean peninsula using national standard climate change scenarios and the ETCCDI index. Korean Society of Hazard Mitigation, Vol. 19, No. 7, pp. 105-115.

Kim, B.K., and Kim, B.S. (2009). Analysis of impact climate change on extreme rainfall using $\mathrm{B} 2$ climate change scenario and extreme indices. KSCE Journal of Civil and Environmental Engineering Research, Vol. 29, No. 1, pp. 23-33.

Kim, B.K., Kim, B.S., and Kim, H.S. (2008). On the change of extreme weather event using extreme indices. $K S C E$ Journal of Civil and Environmental Engineering Research, Vol. 28, No. 1, pp. 41-53.

Kim, B.S., Kwon, H.H., and Kim, H.S. (2011). Impact assessment of climate change on drought risk. Journal of Wetlands Research, Vol. 13, No. 1, pp. 1-11.

Kim, Y.J., and Choi, Y.E. (2010). Characteristics and changes of climate extreme events in Jeju-do. Journal of Climate Research, Vol. 5, No. 3, pp. 202-218.

Seo, D.I. (2013). Characteristics of precipitation and temperature in Jeju-do by climate change. Jeju Development Institute, Vol. 17, pp. 49-77.

\begin{tabular}{l|l}
\hline Received & March 16, 2021 \\
\hline Revised & March 17, 2021 \\
\hline Accepted & June 22, 2021
\end{tabular}

